\title{
Follicular Unit Extraction in Management of Secondary Cicatricial Alopecia
}

\author{
Mahmoud Mohamed Said, ${ }^{1}$ M.B.B.Ch, Abdel Monem Hussein Hoota, ${ }^{1}$ MD, \\ Abdel Nasser Abdel Rahman Khallaf, ${ }^{1}$ MD.
}

\author{
* Corresponding Author: \\ Mahmoud Mohamed Said \\ m.said.empire@gmail.com
}

Received for publication July 16 2021; Accepted August 21, 2021; Published online August 21, , 2021.

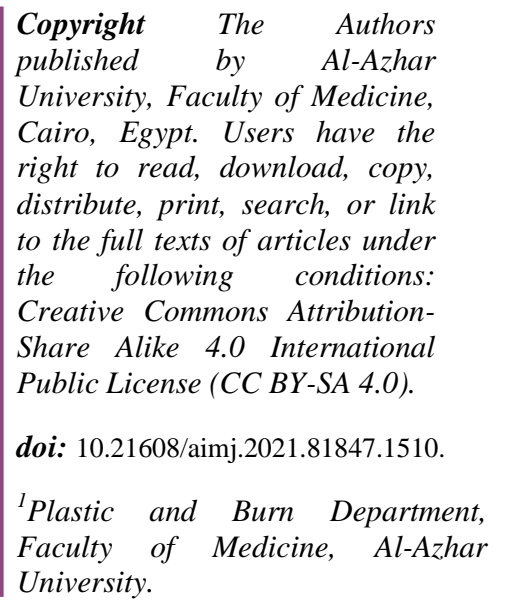

Copyright The Authors University, Faculty of Medicine, Cairo, Egypt. Users have the right to read, download, copy the following conditions: Creative Commons AttributionShare Alike 4.0 International doi: $10.21608 /$ aimj.2021.81847.1510 Faculty of Medicine, Al-Azhar University.

\begin{abstract}
Background: Management of Cicatricial alopecia has been a challenge to plastic surgeons nowadays ,the variability of surgical methods makes it difficult to choose the right treatment for each patient, also proper diagnosis of the type of cicatricial alopecia, whether it is primary or secondary, reversible or irreversible, scaring or non-scaring and stable or unstable, needs certain experience and skills.

Aim of the study: To assess results of Follicular Unit Extraction in management of secondary cicatricial alopecia.

Patients and Methods: This prospective cohort study, on 20 patients with secondary cicatricial alopecia. These Patients were operated upon in the Plastic Surgery and burn department, Al-Azhar University Hospitals and were referred to our outpatient clinic for follow up visits.

Results: There was sixteen $(80 \%)$ males and four $(20 \%)$ females, the mean age of the studied cases was $18.85( \pm 2.94 \mathrm{SD})$ with range $(15-25)$ years. General outcome there were two (10\%) bad, six (30\%) good and twelve $(60 \%)$ very good, according to hair density there were one $(5 \%)$ poor, thirteen $(65 \%)$ good and six $(30 \%)$ very good, according to postoperative scars there were eighteen $(90 \%)$ low and two (10\%) high and according to hair direction there were four (20\%) bad, eleven (55\%) good and five $(25 \%)$ very good. Among the studied cases there were nine $(45 \%)$ who needed another surgery.

Conclusion: Study concluded that hair transplantation is very useful in the field of cicatricial alopecia treatment, hair transplantation has less hazards during anesthesia, less post-operative scars and less recovery time than the usual method of hair restoration.
\end{abstract}

Keywords: Follicular Unit Extraction; Secondary Cicatricial Alopecia; hair transplantation.

Disclosure: The authors have no financial interest to declare in relation to the content of this article. The Article Processing Charge was paid for by the authors.

Authorship: All authors have a substantial contribution to the article.

\section{INTRODUCTION}

The term "cicatricial alopecia" refers to a scarring that ends up with loss of hair that outcomes from a various set of disorders that devastate the hair follicle, substitute it with scar tissue, and cause persistent hair loss. ${ }^{1}$

Cicatricial alopecias are sorted as primary and secondary. In primary cicatricial alopecias the stable portion of the hair follicle (stem cells of the bulge area and the infundibulum) is the target of the destructive inflammatory disease and the cause varies from autoimmune diseases Lichen Plano Pilaris (LPP), Discoid Lupus Erythematosus (DLE), pseudopelade of brocq), to infections like folliculitis decalvans. $^{2}$
Secondary cicatricial alopecias, result from damage of the hair follicle subsidiary to a Non-follicledirected

process or external injury, such as burns, radiation, trauma or severe infections like tinea capitis. ${ }^{3}$

Surgical correction of cicatricial alopecias is highly valuable. While the affected area is most often treated with hair transplantation, alternative approaches include alopecia reductions (the excision of the hairless region) and/or flap procedures, alone or sometimes in conjunction with hair transplanting. ${ }^{1}$

The era of hair restoration surgery commenced in Japan with techniques developed to treat burn survivors. In the 1930s, Okuda published his technique of transplanting hairs derived from punch grafts. $^{4}$ 
Hair transplant consists of harvesting hair from a donor area (usually the occipital and posteroparietal scalp) using a single strip excision or small punch excisions used to harvest individual follicular units (FUE) and grafting them into the recipient site. ${ }^{5}$

Hair transplantation has proven efficacy in cases of androgenetic alopecia with the advantage of minimal scarring, but it requires good donor area, the application of this method has been adebate in many studies in the face of traditional methods of scar excision, tissue expanding \& flap surgeries. ${ }^{6}$

Aim of the work was to assess results of Follicular Unit Extraction in management of secondary cicatricial alopecia.

\section{PATIENTS AND METHODS}

This interventional clinical study - prospective cohort study, on 20 patients with secondary cicatricial alopecia. These Patients were operated upon in the Plastic surgery and burn department, AlAzhar University Hospitals and were referred to our outpatient clinic for follow up visits.

All patients were subjected routinely to Consent and routine clinical assessment and pre-operative investigations.

Inclusion criteria: Age range 15 to 35 years old, having secondary cicatricial alopecia, and scalp defect from area $5 \mathrm{~cm}^{2}$ to $45 \mathrm{~cm}^{2}$.

Exclusion criteria: Patients with total loss of scalp area, patients under 15 years old and over 35 years old, patients with cardiac disease, patients with blood diseases, and patients with liver viral infections.

\section{Pre-Operative Preparation:}

Hair shaving on a length of $1 \mathrm{~mm}$ over the skin: Patient should have a shower in the day of the operation and to be operated under complete aseptic condition. The patient should wash his head completely with Betadine (Bovidine Iodine) Shampoo just 10 minutes before surgery and drying with dry sterile towels.

Pre-operative photographing: Recording the vital signs of the patient (Pulse, B.P.) one hour preoperatively was done to know his/her base line and to detect any abnormalities in vital signs during surgery.

Pre- Operative medication: Intravenous Canula. $500 \mathrm{cc}$ glucose as slowly drips. Analgesics and sedatives: Phenaramine $2 \mathrm{~mm}^{3}$ I.V. one hour preoperatively as a sedative and anti-allergic together with IM. Injection of non-steroidal anti-inflammatory analgesic, Diclofenac sodium $75 \mathrm{mg}$ tab as moderate pain killer during the operation and to minimize the Post-operative pain. Combined prophylactic Broad spectrum antibiotics to guard against gram +ve and gram -ve organisms such as: Sulbctam and Amoxicillin 1.5gm vial IV, Gentamycin 80mg Amp.

\section{Post-operative treatment and follows up:}

All patients are given Broad spectrum antibiotics Sulbctam and Amoxicillin $1.5 \mathrm{gm}$ vial IV for one week. Oral analgesic is prescribed in the form of NSAIDs Ibuprofen $600 \mathrm{mg}$ tab t.d.s. for one week. H2 blocker (Ranitidine $150 \mathrm{mg}$ Tablet) twice daily is prescribed to prevent any gastro-intestinal upset with medication. Some patients are advised to put ice bags over the eyes and forehead for the 1st 48 hours to prevent oedema. The first Post-operative dressing was done 3 days later, the patient came to the outpatient clinic and the dressing is removed very slowly under running saline. The patients start washing the scalp by anti-dandruff shampoo 3 days after dressing removal. Patients are given vitamin $B_{7}$ (Biotin $10000 \mathrm{IU}$ ) once daily for 6 months. Two cases received monthly platelet rich plasma injection to the recipient area for 6 months. Photographing of both donor and recipient areas at every visit.

\section{Patient Satisfaction:}

All patients are subjected to a five point questionnaire -after six months follow up- measuring their opinion in:

The surgery they underwent,

Hair density at the treated area,

Proper hiding of the scars post operatively,

Hair direction related to its new position

How much they advise other patients with same degree of cicatricial alopecia to go for the same surgery.

\section{Statistical analysis:}

Statistical analysis Data were analyzed by Statistical Package of Social Science (SPSS), software version 22.0 (SPSS Inc., 2013). Continuous data were expressed as Mean $\pm \mathrm{SD}$, while the nominal data were presented by the frequency and percentage. The unpaired-samples $t$-test (independent t-test): compares the means between the two groups of patients regarding age, Surface area of alopecia $\left(\mathrm{Cm}^{2}\right)$, Time since injury (years) and Operative duration (hours). The chi-square test of association is used to discover if there is a relationship between the duration of operation and incidence of complication. In addition, it was used to distinguish the association between the size of alopecia and incidence of complication. - The Fisher's exact test: is used instead of a chi-square test if one or more of the cells has an expected frequency of five or less. In all testes used $\mathrm{P}$ value $<0.05$ considered significant.

\section{RESULTS}

Among the studied cases there was sixteen $(80 \%)$ males and four $(20 \%)$ females, the mean age of the studied cases was $18.85( \pm 2.94 \mathrm{SD})$ with range (1525) years.

According to cause of injury among the studied cases there were nine $(45 \%)$ due to trauma scar, one $(5 \%)$ 
due to surgical scar, two (10\%) due to post expander and eight (40\%) due to burn and according to cause of injury among the studied cases there were five (25\%) temporal, four (20\%) parietal, two (10\%) occipital, three $(15 \%)$ frontal, three $(15 \%)$ temp + parietal, two $(10 \%)$ at occipital + sagittal and one (5\%) frontal + temporal.

Among the studied cases there were eighteen $(90 \%)$ who had one operation and two (10\%) who had two operations, with mean operation time $3.05( \pm 1.40$ SD) with range (1-5.5) (Table 1).

The mean number of grafts of studied cases was $420.0( \pm 276.92$ SD) with range (150-1200). The mean area of the alopecia of studied cases was 17.15 $( \pm 9.92 \mathrm{SD})$ with range $(5-45) \mathrm{cm}^{2}$. The mean survived/inserted $\%$ of studied cases was $74.91( \pm 8.08$ $\mathrm{SD})$ with range $(60-85.58)$. The mean time since injury of studied cases was 11.45 ( $\pm 6 \mathrm{SD}$ ) with range (2-20) (Table 2).

According to general outcome there were two (10\%) bad, six $(30 \%)$ good and twelve $(60 \%)$ very good, according to hair density there were one $(5 \%)$ poor, thirteen (65\%) good and six (30\%) very good, according to postoperative scars there were eighteen $(90 \%)$ low and two (10\%) high and according to hair direction there were four $(20 \%)$ bad, eleven $(55 \%)$ good and five $(25 \%)$ very good. Among the studied cases there were nine (45\%) who needed another surgery (Table 3 ).

The mean inserted of studied cases was $22.51( \pm 3.20$ SD) with range (18.2-30) and the mean survived was $16.75( \pm 2.07 \mathrm{SD})$ with range (13-21). There was high statistically significant difference between mean inserted and mean survived $(\mathrm{p}<0.001)$ (Table 4).

\begin{tabular}{|l|l|l|}
\hline & No. & $\%$ \\
\hline Sex & \multicolumn{2}{l|}{} \\
\hline Male & 16 & 80.0 \\
\hline Female & 4 & 20.0 \\
\hline Age (years) & \multicolumn{2}{l|}{} \\
\hline Min. - Max. & $15.0-25.0$ & \\
\hline Mean \pm SD. & $18.85 \pm 2.94$ & $\%$ \\
\hline Median (IQR) & $18.0(16.50-21.0)$ & \\
\hline & No. & 45.0 \\
\hline Cause of injury & \multicolumn{2}{l|}{} \\
\hline Trauma scar & 9 & 5.0 \\
\hline Surgical scar & 1 & 10.0 \\
\hline Post expander & 2 & 40.0 \\
\hline Burn & 8 & \\
\hline Site of injury & & 25.0 \\
\hline Temporal & 5 & 20.0 \\
\hline Parietal & 4 & 10.0 \\
\hline Occipital & 2 & 15.0 \\
\hline Frontal & 3 & 15.0 \\
\hline Temp + Parietal & 3 & 10.0 \\
\hline Occipital + Sagittal & 2 & 5.0 \\
\hline Frontal + Temporal & 1 & \\
\hline Number of operations & & 90.0 \\
\hline 1 & 18 & 10.0 \\
\hline 2 & 2 & \\
\hline Operative duration (hours) & & \\
\hline Min. - Max. & $1.0-5.50$ & \\
\hline Mean \pm SD. & $3.05 \pm 1.40$ & \\
\hline Median(IQR) & $2.75(2.0-4.0)$ & \\
\hline & & \\
\hline
\end{tabular}

Table 1: Distribution of the studied cases according to demographic data, studied cases according to cause of injury, site of injury, number of operations and operative duration $(n=20)$.

\begin{tabular}{|c|c|c|c|}
\hline & Min. - Max. & Mean \pm SD & Median(IQR) \\
\hline Number of grafts & $150.0-1200.0$ & $420.0 \pm 276.92$ & $\begin{array}{l}350.0 \\
(200-575.0)\end{array}$ \\
\hline $\begin{array}{l}\text { Area of the } \\
\text { alopecia }(\mathrm{cm} 2)\end{array}$ & $5.0-45.0$ & $17.15 \pm 9.92$ & $\begin{array}{l}15.0 \\
(10.0-23.0)\end{array}$ \\
\hline $\begin{array}{ll}\text { Inserted } & \text { /survived } \\
(\mathrm{grafts} / \mathrm{cm} 2) \% & \end{array}$ & $60.0-85.58$ & $74.91 \pm 8.08$ & $\begin{array}{l}76.19 \\
(69.33-81.50)\end{array}$ \\
\hline Time since injury & $2.0-20.0$ & $11.45 \pm 6.0$ & $\begin{array}{l}12.0 \\
(6.0-15.0)\end{array}$ \\
\hline
\end{tabular}

Table 2: Descriptive analysis of the studied cases according to number of grafts, area of the alopecia, survived/inserted $\%$ and time since injury $(\mathrm{n}=20)$. 


\begin{tabular}{|l|l|l|}
\hline & No. & $\%$ \\
\hline General & & 10.0 \\
\hline Bad & 2 & 30.0 \\
\hline Good & 6 & 60.0 \\
\hline Very good & 12 & \\
\hline Hair density & & 5.0 \\
\hline Poor & 1 & 65.0 \\
\hline Good & 13 & 30.0 \\
\hline Very good & 6 & \\
\hline Postoperative scars & & 90.0 \\
\hline Low & 18 & 10.0 \\
\hline High & 2 & \\
\hline Hair direction & & 20.0 \\
\hline Bad & 4 & 55.0 \\
\hline Good & 11 & 25.0 \\
\hline Very good & 5 & \\
\hline Need for another surgery & & 55.0 \\
\hline No & 11 & 45.0 \\
\hline Yes & 9 & \\
\hline
\end{tabular}

Table 3: Distribution of the studied cases according to outcomes $(n=20)$.

\begin{tabular}{|c|c|c|c|c|}
\hline & $\begin{array}{l}\text { Mean } \\
(\text { grafts/cm2) }\end{array}$ & $\begin{array}{ll}\text { Mean } & \text { survived } \\
(\text { grafts/cm2) } & \\
(\mathrm{n}=20) & \end{array}$ & $\mathrm{t}$ & $\mathrm{p}$ \\
\hline Min. - Max. & $18.20-30.0$ & $13.0-21.0$ & \multirow[t]{3}{*}{$10.069 *$} & \multirow[t]{3}{*}{$<0.001 *$} \\
\hline Mean \pm SD & $22.51 \pm 3.20$ & $16.75 \pm 2.07$ & & \\
\hline Median (IQR) & $\begin{array}{l}22.0 \\
(21.0-23.30)\end{array}$ & $\begin{array}{l}17.0 \\
(15.50-18.0)\end{array}$ & & \\
\hline
\end{tabular}

Table 4: Comparison between mean inserted and mean survived. (t: Paired t-test, p: p value for comparing between mean inserted and mean survived, *: Statistically significant at $\mathrm{p} \leq 0.05$ ).

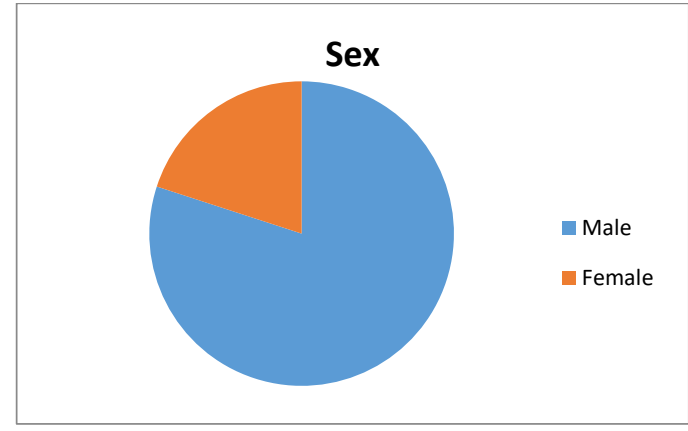

Fig 1: Distribution of the studied cases according to sex..

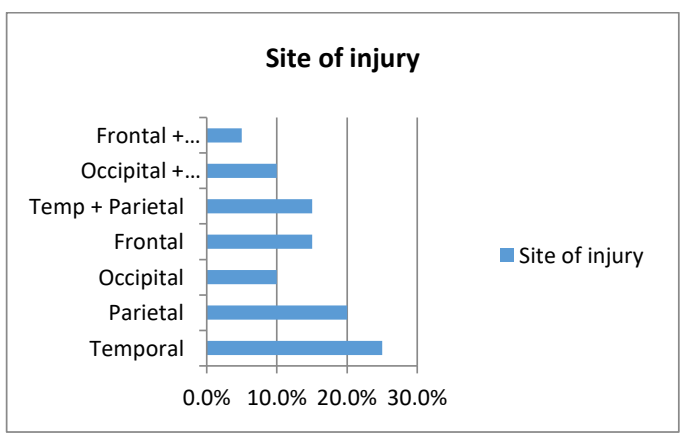

Fig 2: Distribution of the studied cases according to Site of injury.

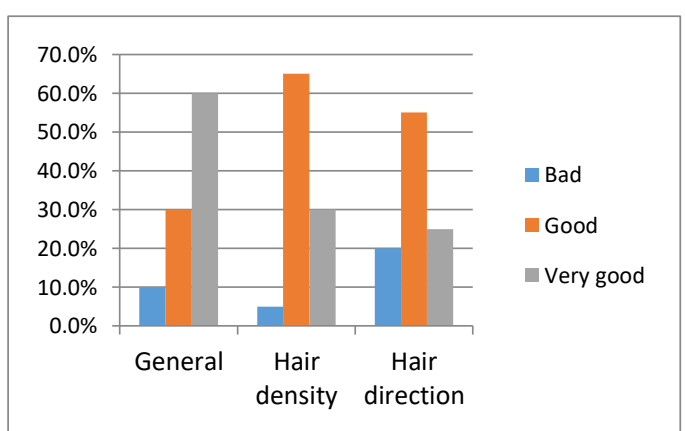

Fig 3: Distribution of the studied cases according to outcomes.

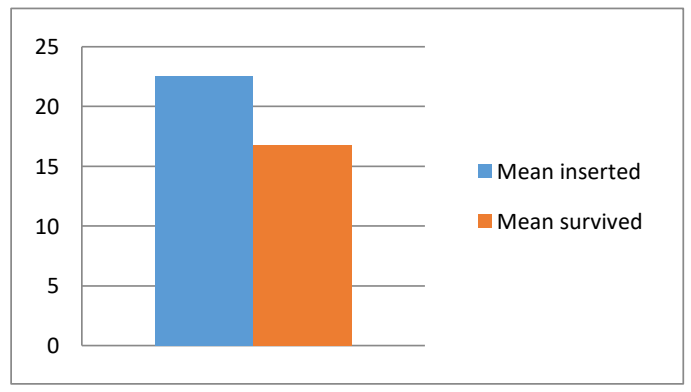

Fig 4: Comparison between mean inserted and mean survived. 


\section{Case Presentation}

Case 1

Male patient 25 years with post follicular unit transplantation (FUT) scar in the occipital area treated with hair transplantation of 500 graft.

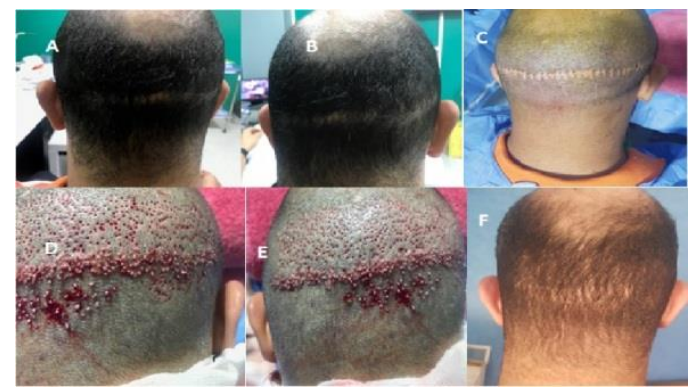

Fig 5: Case $1 \quad(\mathrm{~A}, \mathrm{~B} \quad, \mathrm{C})$ pre-operative(D,E) immediately after graft insertion. (F) 6 months postoperative.

\section{Case 2}

Male patient 17 years old with trauma scar in the tempoparietal region about $9 \mathrm{~cm} 2$ treated by hair transplantation of 200 graft.
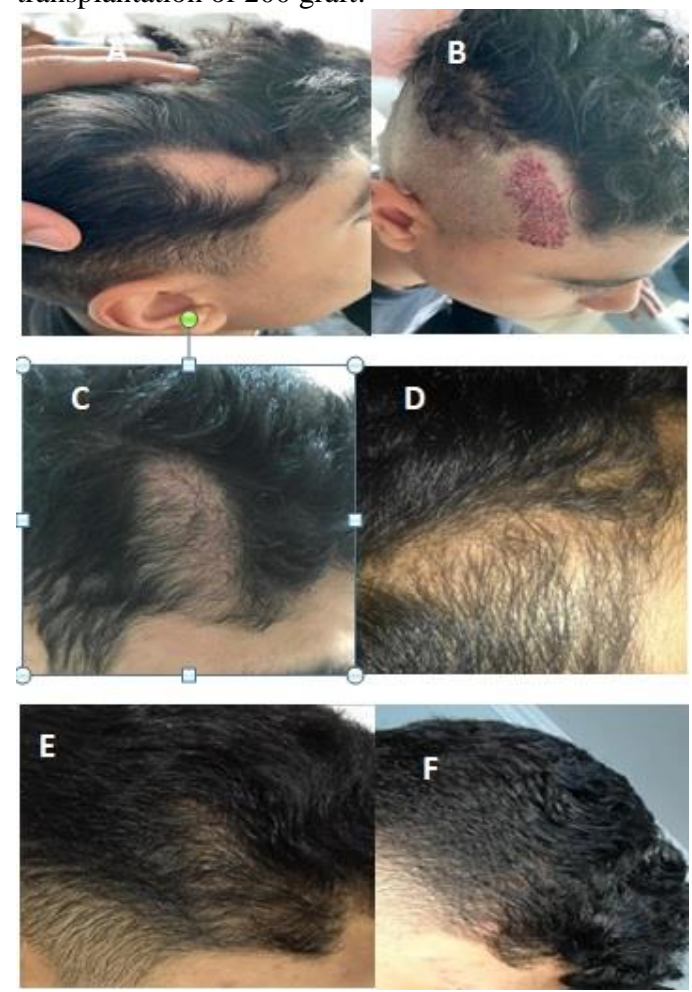

Fig 6: case 2 (A) preoperative (B) immediately after graft insertion, (C) one month postoperative (D) 2 months postoperative, (E) 4 months postoperative (F) 6 months postoperative.

\section{Case 3:}

Male patient 18 years old with post burn scar in the parietal region treated by hair transplantation of 650 grafts.
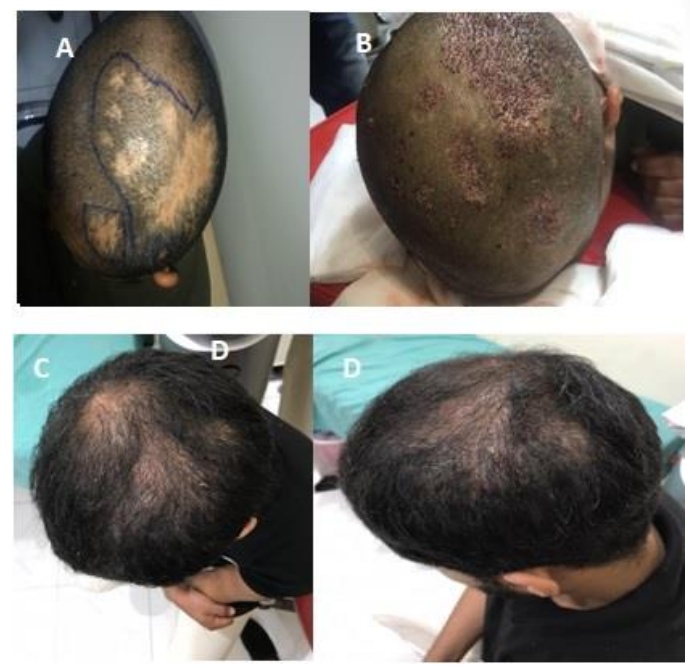

Fig 7: Case 3 (A) pre-operative (B) after hair implantation, (C,D) 6 months postoperative.

\section{Case 4:}

Male patient 16 years old suffering from trauma scar due to previous cut wound of $16 \mathrm{~cm} 2$ at the right parieto-temporal region treated by hair transplantation of 350 grafts.
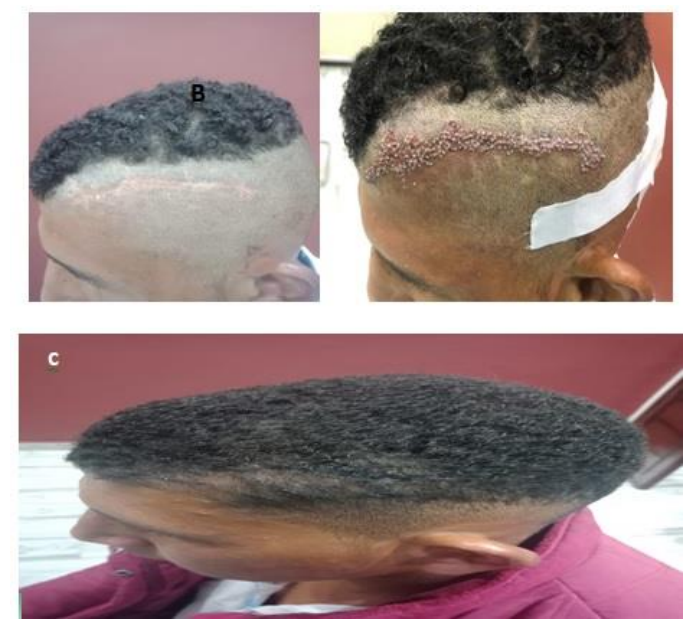

Fig 8: Case 4 (A) pre-operative (B) after hair implantation (C) 6 months post-operative.

\section{DISCUSSION}

Hair transplantation surgery is the cosmetically relevant therapy currently that can permanently give back naturally looking scalp hair in patients, where medication is not an option. However, the quality of the result is highly dependent on the patient (age, availability of grafts, and prospected progress of alopecia) and the technique of the surgeon. Although, there is a great variation in how surgeons perform aspects of the transplantation procedure in detail, the strategy used for the obtainment of grafts, in both cases being intact follicular units (FUs), roughly defines 2 techniques: follicular unit transplantation (FUT) and follicular unit extraction (FUE). ${ }^{7}$ 
As with all procedures, the consult is vital to establish candidate selection. Patients with increased donor density, thick-caliber hair follicles, and areas of clear thinning in the frontal scalp are ideal candidates for the procedure. Those with limited donor density and fine thin-caliber hair follicles will have less cosmetic impact from a procedure. ${ }^{8}$

Hair transplantation in alopecic areas caused by an active primary scarring disease is contraindicated There may be some selected cases where hair transplantation can be contemplated. This procedure can be considered in primary cicatricial (scarring) alopecias, which has burnt out or has become inactive for years without medication. The growth rates are much lower than with hair transplantation for common indications, such as androgenetic pattern hair loss. Even after acceptable graft survival rates after surgery, there may still be the possibility of disease recurrence, which may lead to the transplanted grafts being affected by the underlying disease process. ${ }^{9}$

Scarring alopecias from secondary causes, such as burns, surgery and trauma, are mostly amenable to hair transplantation. Follicular unit grafts transplanted over scars in hair-bearing areas provide camouflage resulting in an improved cosmetic appearance, especially in highly visible areas, such as the scalp. Important considerations include wider spacing of grafts compared with regular hair transplantation of androgenetic pattern hair loss because of the decreased vascularity over these scarred areas. Staged procedures can be done to increase density and improve coverage. ${ }^{10}$

Successful outcomes have been observed with follicular unit transplantation to hide scars and restore hairs lost from rhytidoplasty and other plastic surgeries. ${ }^{11}$

In this study we selected 20 patients suffering from cicatricial alopecia, they were 16 males $(80 \%)$ and 4 females $(20 \%)$. Patient age ranged from 15 to 25 years old, the causes of alopecia was post burn scar in 8 cases $(40 \%)$, post traumatic scar in 9 cases $(45 \%)$, post-surgical scar in 2 cases $(5 \%)$ and two cases after skin expander (10\%).

Shao et al. ${ }^{12}$ carried their study on 37 patients suffering from secondary cicatricial alopecia in a duration of 5 years, in our study we studied 20 patients operated by hair transplantation in a period of 12 months this might be due to rare presentation of the patients and longtime of follow up needed for these patients.

Regarding patient's mean age it was $18.85 \pm$ 2.94.while Shao et al. ${ }^{12}$ showed mean age of $24.68 \pm 5.88$ this difference might be due to bigger sample size.

In this study The mean surface area of alopecia $\left(\mathrm{Cm}^{2}\right)$ was $17.15 \pm 9.92$, which differs from results told by Shao et al. ${ }^{12}$ as surface area of recipient site has the mean of $10.08 \pm 19.55$ this might be due to their case selection (choosing patients with small linear scalp scars).

In current study, the mean duration of hair transplantation was $3.05 \pm 1.40$, Shao et al. ${ }^{12}$ has a similar range of operative duration (3.61 \pm 1.32$)$.

In the current study, the mean follicular unit density per recipient area was $22.51 \pm 3.28 \mathrm{fu} / \mathrm{cm}^{2}$, while Shao et al. ${ }^{12}$ had the mean density of $36.28 \pm 6.44 \mathrm{fu} / \mathrm{cm}^{2}$ the difference was due to our consideration of the poor vascularity of the recipient areas so we didn't overcrowd the follicular units during implantation.

Concerning complications, while the donor sites showed no complications (white scar, pseudosyphilitic appearance or necrosis) there was minor complications in the recipient sites $(15 \%)$, Hair thinning (5\%, one case), un-satisfaction $(10 \%$, two cases).

In this study, patients had a complication rate of $15 \%$ while Shao et al. ${ }^{12}$ had only $5.6 \%$ incidence of complication this difference might be because he only mentioned long term complications including 2 patients out of 37 patients having epidermoid cyst formation.

There were no significant association between the size of alopecia and incidence of complication ( $p$ values of Fisher's exact test were 0.59 and 0.64 respectively). In addition, $\mathrm{p}$ values of Pearson Chisquare were 0.08 and 0.55 respectively).

Furthermore, no association could be detected between operative duration and incidence of complication, as $\mathrm{p}$ value of Fisher's exact test is 0.076 and $p$ value of Pearson Chi- square is 0.08 (not significant).

Regarding patient satisfaction: In general no patient assigns excellent results, very good results reported in 12 cases $(60 \%)$, good results was revealed in 6 cases $(30 \%)$, bad results in two cases $(10 \%)$. Hassan et al. ${ }^{13}$ showed excellent results in $10 \%$, good results in $70 \%$, and satisfactory results in $20 \%$ of patients, while Shao et al. ${ }^{12}$ stated that patient Satisfaction at their study was $100 \%$ for 30 patients, $90 \%$ to $100 \%$ for five patients and $<90 \%$ for two patients

\section{CONCLUSION}

Management of secondary scarring cicatricial alopecia has multiple choices, a good surgeon is who can choose from several options the adequate one for his patient. Multiple factors interfere with the surgical plan age, gender, occupation, size and site of alopecia and time since injury. Multiple sessions are often needed to reach the optimum solution for this problem.

In our study, we concluded that hair transplantation is very useful in the field of cicatricial alopecia treatment, hair transplantation has less hazards during anesthesia, less post-operative scars and less 
recovery time than the usual method of hair restoration.

The use of hair transplantation after skin expansion would also be of great value to the patient to cover linear post-operative scars following expansion surgeries.

\section{REFERENCES}

1. Ross EK, Tan E and Shapiro J. Update on primary cicatricial alopecias. Journal of the American Academy of Dermatology. 2005; 53(1): 1-37.

2. Tan E, Martinka M, Ball N, et al. Primary cicatricial alopecias: clinicopathology of 112 cases. Journal of the American Academy of Dermatology. 2004; 50(1): 25-32.

3. Sowjanya CL, Rao TN, Guruprasad P et al. Clinico-pathological study of acquired primary cicatricial alopecias. Journal of Dr. NTR University of Health Sciences. 2012; 1(1): 21-7.

4. Farjo, B, Farjo N, Williams, G. Hair transplantation in burn scar alopecia. Scars, Burns \& Healing. 2015; 1: 205-12.

5. Meyer-Gonzalez $\mathrm{T}$ and Bisanga C. Body-hair transplant for cicatricial alopecia. Actas DermoSifiliográficas (English Edition). 2012; 103(2): 163-5.

6. Unger $\mathrm{W}$, Unger R and Wesley C. The surgical treatment of cicatricial alopecia. Dermatologic Therapy. 2008; 21(4): 295-311.

7. Azar RP, Thomas AH, Maurer $M$, et al. Alterations in hair follicle morphology and hair shaft production after follicular unit transplantation. Am J Dermatopathol. 2016; 38(10): 732-8.

8. Avram MR, Finney $R$ and Rogers N. Hair transplantation controversies. Dermatol Surg. 2017; 43(2): 158-62.

9. Bunagan MJ, Banka $\mathrm{N}$ and Shapiro J. Hair transplantation update: procedural techniques, innovations, and applications. Dermatol Clin 2013; 31(1):141-53.

10. Barr L and Barrera A. Use of hair grafting in scar camouflage. Facial Plast Surg Clin North Am. 2011; 19: 559-68.

11. Radwanski HN, Nuns D and Nazina F. Follicular transplantation for the correction of various stigmas after rhytidoplasty. Aesthetic Plast Surg. 2007; 31:62-8.

12. Shao H, Hang H, Yunyun J, et al. : Follicular unit transplantation for the treatment of secondary cicatricial alopecia. Plastic Surgery. 2014; 22(4): 249-53.

13. Hassan I, Abdullah Z and Keen A. Hair Transplantation in Cicatricial Alopecia: A Preliminary Report. J Turk Acad Dermatol. 2014; 8: $1-4$. 